\title{
Design, Development and Performance Evaluation of a Seed Paddy Cleaning Machine
}

\author{
P.D. Kahandage ${ }^{1}$, G.V.T.V. Weerasooriya ${ }^{1 *}$, V.P. Ranasinghe ${ }^{1}$, E.J. Kosgollegedara ${ }^{1}$, S.D.S. Piyathissa ${ }^{2}$
}

${ }^{1}$ Department of Agricultural

Engineering and Soil Science, Faculty of Agriculture, Rajarata

University of Sri Lanka,

Puliyankulama, Anuradhapura,

Sri Lanka.

${ }^{2}$ University College of

Kuliyapitiya, University of

Vocational Technology,

Kuliyapitiya, Sri Lanka.

\section{Correspondence:}

*gvtvw@agri.rjt.ac.lk

https://orcid.org/0000-0001-8911-7675

DOI: http://doi.org/10.4038/sljae.v3i2.78

\begin{abstract}
Rice (Oryza sativa L.) is the staple food crop in Sri Lanka occupying 34\% of the total cultivated area. Seed paddy production is one of the major economic activities in the paddy sector, which is fully mechanized only at the large-scale level. Unavailability of an affordable mechanical solution is a big barrier for entering small and medium scale producers in to the seed paddy industry. Therefore, the aim of this study was to introduce an efficient and affordable electrical motor driven small or medium scale paddy cleaning machine for seed paddy production. The main components of the machine are paddy sieving unit, blowing unit and stone separator. According to the variety of paddy, the sieve size of the sieving unit can be changed. The performance of the machine was evaluated using paddy samples with purposely added light and heavy impurities such as straw particles and different sized stones. The suitable speeds for the better operation of sieve, separator and blower were 90, 200 and $960 \mathrm{rpm}$, respectively. The separation percentages of the large, light, and same size impurities were $96 \%, 74 \%$, and $86 \%$, respectively. The effective capacity of the machine was $252 \mathrm{kgh}^{-1}$ with $79 \%$ mechanical efficiency. Based on the overall satisfactory performance, the newly built paddy cleaning machine can be recommended to small and medium scale paddy farmers in Sri Lanka. The machine can be further developed with a magnetic separator for removing iron particles.
\end{abstract}

Keywords: Effective capacity, Paddy cleaning, Seed paddy, Stone separator 


\section{Introduction}

Paddy, the second largest produced cereal in the world is the staple food crop in most countries. There are over 144 million rice farms worldwide on a harvested area of about 158 million hectares. World Rice Production in 2017 was 508.6 million metric tons (Shahbandeh 2017). According to the per capita consumption of rice, Myanmar, Lao People's Democratic Republic, Viet Nam, Bangladesh, Cambodia and Indonesia are considered as very high rice consuming countries (>200 kg year-1) while Thailand, Philippines, Sri Lanka, Sierra Leone, Republic of Korea, Nepal, Madagascar, China, Gambia, Malaysia, Guinea-Bissau, Guyana, Maldives, Brunei Darussalam, Suriname, Democratic People's Republic of Korea, Côte d'Ivoire, India, Senegal, China-Macao and Costa Rica are under high rice consuming countries (100200 kg year-1) (Nguyen 2020).

Paddy is cultivated in two seasons as Yala and Maha in Sri Lanka based on the rainfall. Totally, 870,000 ha of paddy fields are cultivated annually in Sri Lanka, as 560,000 ha in the Maha season and 310,000 ha in the Yala season engaging 1.8 million farm families. Current annual rice production of Sri Lanka is about 2.7 million tons of rough rice, and it satisfies only 95 percent of the domestic requirement (DOA 2014).
Since, seeds are living product, correct handling of seeds directly affect to their viability and subsequently for the crop productivity. As well, good quality seeds can increase the yield considerably. Seed paddy production of Sri Lanka is mainly handed by the private/government paddy producers or individual farmers.

Seed paddy may contain various amounts of other crop seeds, straw, chaff, sand, rocks, dust, immature grains, and iron or steel particles. Those impurities are incorporated into seeds during harvesting, threshing, and handling. Cleaning is a material separation process, and the objective of cleaning is to separate undesirable foreign materials from the seed paddy and leave a cleaned seed paddy for storage and processing. When producing seed paddy, cleaning is an essential step of processing to reach the standards. Almost every farmer of Sri Lanka is aware of the need of good seeds and their contribution to higher yields. The total seed paddy requirement of the country at present is about 4.4 million bushels (Weerasena and Madawanarachchi 2014).

Despite having several large-scale paddy cleaning machines, which belong to large scale private companies in Sri Lanka, small or medium scale seed paddy cleaning 
machines are not available in an affordable price as most of them are imported.

The higher initial cost of large-scale paddy cleaners is the major barrier for entering the small or medium scale paddy farmers to the seed paddy producing industry, which makes a monopoly of large-scale companies to determine the price of seed paddy. An affordable mechanical solution for small scale seed paddy farmers is a major concern under local conditions. Therefore, this study was to introduce an efficient and affordable mechanical solution for cleaning paddy. This would facilitate small and medium scale paddy farmers entering the seed paddy processing industry in Sri Lanka.

\section{Materials and Methods}

\section{Design Concept}

The machine was designed to complete the cleaning process of paddy for the purpose of producing seed paddy by three steps. At the first step of cleaning, large size impurities such as weed seeds, stones, paddy seeds of other varieties, were expected to remove. A suitable size sieve which can be changed according to the variety, connected with an eccentric shaft and powered by an electric motor, which was the main power source, was designed for the first task. At the second step, light impurities such as, straw particles, chaff and unfilled seeds were supposed to be removed by the mean of a blown air flow. An electrically driven air aspirator was designed to perform the second task. The third step was removing the same size impurities with different densities such as stones, metal particles using a vibrated stone separator connected to the main power source. All the three steps were designed to perform simultaneously as a continuous process.

\section{Designing of the Machine}

Affordability for small and medium scale farmers, durability, higher capacity and efficiency and safety in operations were the highly considered design factors of this machine. The machine was comprised with four major systems as large size, light and same size or smaller impurities separation system and power transmission system (Fig.1).

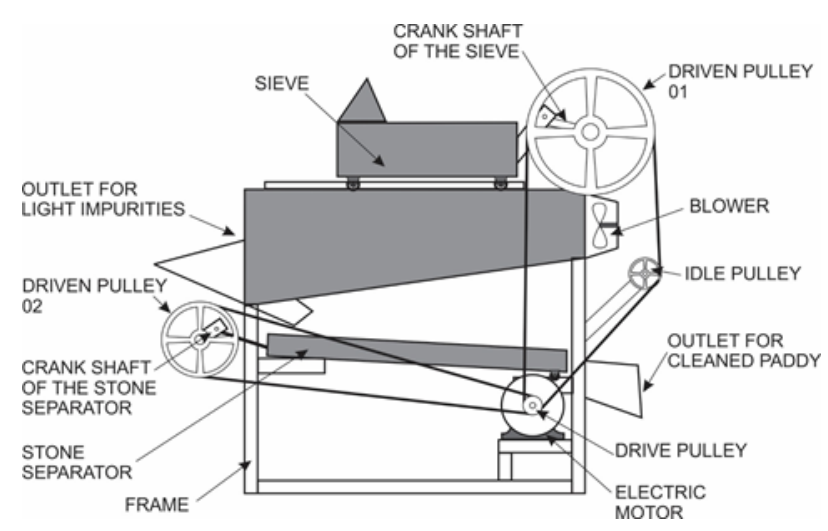

Figure 1: Side view of the designed seed paddy cleaning machine 


\section{Designing of the Large Impurities}

\section{Separation System (LSISS)}

A sieve with changeable mesh size was designed to separate the large size impurities of the harvested paddy. The designed capacity of the container of the sieve was $10 \mathrm{~kg}$ of paddy and sieving can be continuously done facilitating loading of paddy when it is operating.

Some physical properties of paddy were used in designing of the sieve. The bulk density of paddy ranges from $522 \mathrm{kgm}^{-3}$ to $566 \mathrm{kgm}-3$ at the moisture content of $7.19-$ 28.28\% (Reddy 2004).

Specific volume of paddy

$$
\begin{aligned}
& =1,000,000 \mathrm{~cm}^{3} / 550 \mathrm{~kg} \\
& =1,818.2 \mathrm{~cm}^{3} \mathrm{~kg}^{-1}
\end{aligned}
$$

Therefore, volume of $10 \mathrm{~kg}$ of paddy

$$
\begin{aligned}
& =1,818.2 \times 10 \\
& =18,182 \mathrm{~cm}^{3}
\end{aligned}
$$

It was assumed that, only $1 / 3$ of the space of the sieve should be filled for better operation without any dispersion.

Therefore, total volume of the sieve

$$
\begin{aligned}
& =18,182 \times 3 \\
& =54,545.45 \mathrm{~cm}^{3}
\end{aligned}
$$

Therefore, the dimensions of the container of the sieve were decided as $65 \mathrm{~cm}$ in length, $50 \mathrm{~cm}$ in width and $17 \mathrm{~cm}$ in height.
The rotating crankshaft, which is connected with the power source, makes a continuous forward and backward movement of the sieve to pass the paddy from the wire mesh while retaining the large size impurities. This crankshaft converts the angular motion of the electric motor into linear motion of the sieve container giving $20 \mathrm{~cm}$ linear distance. Figure 2 shows the movement of the crank and the sieve container.
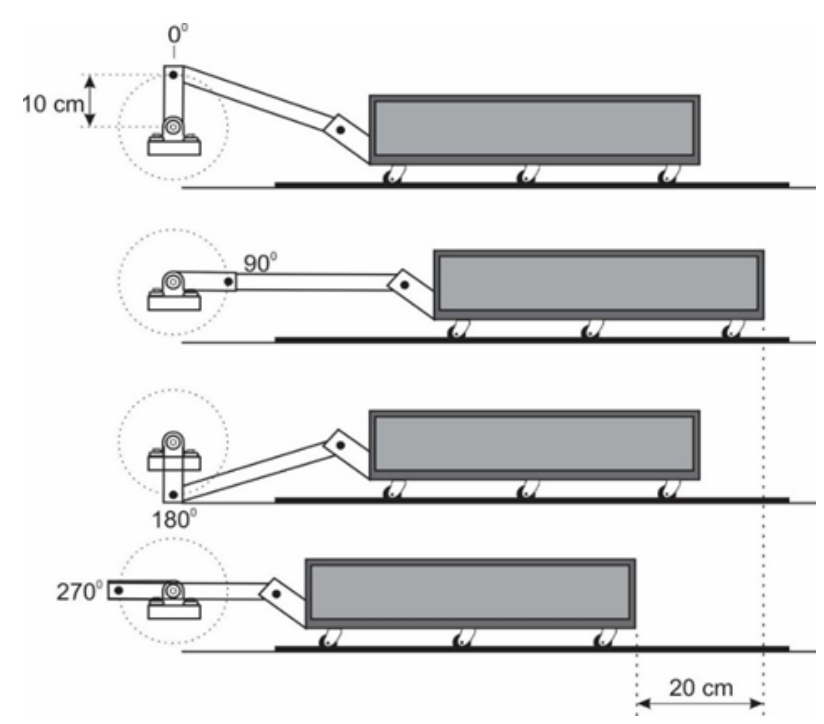

Figure 2: Linear movement of the sieve accordance with the angular motion of the crank

\section{Designing of the Light Impurities Separation System (LISS)}

Air blower working with $960 \mathrm{rpm}$ was used to separate the lighter impurities such as chaff, straw particles and unfilled seeds from paddy coming through the sieve. Therefore, this system is located just below the sieve. The separated light impurities are collected and removed by an outlet located 
in front of the blower. Purified paddy after the second step of cleaning is expected moving to the stone or same size impurities separator under the gravity. Therefore, the bottom of the LISS is sloped 570, in accordance with the angle of repose of paddy which is the angle with horizontal at which the materials is stand when piled (Mohsenin 1978). When the angle of the slope is higher $80-100$ than the angle of repose of paddy, seeds can flow freely under the gravity without any retention (Okunola et al. 2018).

\section{Designing of the Same Size or Small Impurities Separation System (SISS)}

The final step of the cleaning of paddy is separation of the same size or smaller impurities from paddy. A vibrating inclined plate with $117 \mathrm{~cm}$ in length and $44 \mathrm{~cm}$ in width was designed to separate the impurities using density differences. The required vibration of the plate is provided by a crankshaft powered by the main power source.

The first part of the plate, which is closer to the crank shaft, is consisted with number of strips connected to it and other part is connected with a metal sheet with small nodes which is expected for retaining the high-density impurities in grooves in between strips and nodes.

\section{Designing of the Frame}

The frame of the machine was decided to fabricate with mild steel 'L' angled iron. The expected weight of the machine including electric motor and other components was $130 \mathrm{~kg}$. The density and the yield strength of the mild steel were taken as $7.58 \mathrm{gcm}^{-3}$ and $250 \mathrm{MPa}$, respectively (Engineers Edge 2000). The number of the legs of the frame was decided as four while Factor of the Safety (FOS) was considered as five.

Weight acting on one leg of the frame (W)

$$
\begin{aligned}
& =(130 \mathrm{~kg} / 4) \times 9.81 \mathrm{~ms}^{-2} \\
& =318.825 \mathrm{~N}
\end{aligned}
$$

Yield stress of mild steel

$$
=250 \mathrm{MPa}
$$

Therefore, design stress

$$
\begin{aligned}
& =250 \mathrm{MPa} / \mathrm{FOS} \\
& =250 \mathrm{MPa} / 5 \\
& =50 \mathrm{MPa}
\end{aligned}
$$

If the design of the frame is safe, the design stress should be higher than the induced stress.

Therefore, if the minimum cross-sectional area of the L- section is A,

$$
\begin{aligned}
318.825 / \mathrm{A} & =50 \mathrm{MPa} \\
\mathrm{A} & =6.376 \mathrm{~mm}^{2}
\end{aligned}
$$


Therefore, it was decided to select 2" x 2" (4 $\mathrm{mm}$ ) 'L' angled iron for the construction of the main frame of the machine, since stress induced is lower than the design stress. (Shetty et al. 2017).

\section{Designing of the Power Transmission System}

Belt and pulleys system, one of the mechanical power transmission systems was used to transmit the power from the power source to utilizing places. According to Tata (2012), when the distance between shafts is prominent, belts and pulleys are the best solution.

\section{Determination of Sizes of Driven Pulleys}

The relationship between speeds and pulley diameters is given by Equation 1 (Akinnuli et al. 2015).

$\mathrm{N} 1 / \mathrm{N} 2=\mathrm{D} 2 / \mathrm{D} 1$ -(Eq. 1)

Where N1 is speed of the drive pulley, N2 is speed of the driven pulley, D1 is diameter of the drive pulley and D2 is diameter of the driven pulley, respectively.

According to Khurmi and Gupta (2005), the length of an open belt is given by the Equation 2.

$\mathrm{L}=\pi / 2(\mathrm{D} 1+\mathrm{D} 2)+2 \mathrm{C}+[(\mathrm{D} 1+\mathrm{D} 2) 2 / 4 \mathrm{C}]-----(\mathrm{Eq} .2)$
Where, L is length of the belt, D1 and D2 are diameters of two pulleys and $\mathrm{C}$ is the center distance of two pulleys, respectively.

The Table 1 gives the suitable diameters for the driven pulleys and length of the belts for the seed paddy cleaning machine.

Table 1: Diameters of driven pulleys and length of belts

\begin{tabular}{lcccc}
\hline & $\begin{array}{c}\text { Work } \\
\text { ing } \\
\text { speed } \\
\text { (rpm) }\end{array}$ & $\begin{array}{c}\text { Diamete } \\
\text { r (mm) }\end{array}$ & $\begin{array}{c}\text { Center } \\
\text { distance } \\
\text { with } \\
\text { main } \\
\text { drive } \\
\text { (mm) }\end{array}$ & $\begin{array}{c}\text { Length } \\
\text { of the } \\
\text { belt } \\
\text { (m) }\end{array}$ \\
\hline $\begin{array}{l}\text { Main } \\
\text { drive } \\
\text { pulley }\end{array}$ & 1400 & 50 & - & - \\
$\begin{array}{l}\text { Driven } \\
\text { pulley 01 }\end{array}$ & 90 & 780 & 1050 & 3.75 \\
$\begin{array}{l}\text { Driven } \\
\text { pulley 02 }\end{array}$ & 200 & 350 & 800 & \\
\hline
\end{tabular}

The calculated length of the belt of driven pulley 01 was $3.75 \mathrm{~m}$. Therefore, a $4 \mathrm{~m}$ belt and idle pulley were selected to use as a clutch.

\section{Material Selection}

The best material is one which serves the desired objective at the minimum cost. According to Khurmi and Gupta (2005), availability of the materials, suitability of the materials for the working conditions of service and the cost of the materials are the major factors that should be considered when selecting the materials for a machine. Table 2 gives a summary for the selection of 
suitable material for each component of the machine and criteria considered at the selection.

Table 2: Materials and selection criteria for each component

\begin{tabular}{|c|c|c|}
\hline Component & $\begin{array}{l}\text { Criteria for } \\
\text { selection }\end{array}$ & $\begin{array}{l}\text { Selected } \\
\text { material }\end{array}$ \\
\hline $\begin{array}{l}\text { Frame of the } \\
\text { sieve }\end{array}$ & Strength, Cost & $\begin{array}{l}\text { Mild steel } \\
\text { angle iron }\end{array}$ \\
\hline Main Frame & Strength, Cost & $\begin{array}{l}\text { Mild steel } \\
\text { angle iron }\end{array}$ \\
\hline Sieve & $\begin{array}{l}\text { Strength, } \\
\text { Lightness, } \\
\text { Corrosion } \\
\text { resistance }\end{array}$ & $\begin{array}{l}\text { Galvanized } \\
\text { steel wire } \\
\text { mesh }\end{array}$ \\
\hline Cover & $\begin{array}{l}\text { Strength, } \\
\text { Lightness, } \\
\text { Corrosion and } \\
\text { acidic reaction } \\
\text { resistance }\end{array}$ & $\begin{array}{l}\text { Galvanized } \\
\text { steel }\end{array}$ \\
\hline Pulleys & $\begin{array}{l}\text { Strength, cost, } \\
\text { wear resistance } \\
\text { and availability }\end{array}$ & Mild steel \\
\hline Belts & $\begin{array}{l}\text { Flexibility, } \\
\text { strength, wear } \\
\text { resistance, } \\
\text { availability }\end{array}$ & Rubber \\
\hline Bearings & $\begin{array}{l}\text { Axial and radial } \\
\text { load resistance }\end{array}$ & $\begin{array}{l}\text { Pillow journal } \\
\text { bearing }\end{array}$ \\
\hline Shafts & $\begin{array}{l}\text { Workability, wear } \\
\text { resistance, } \\
\text { strength }\end{array}$ & Mild steel \\
\hline
\end{tabular}

\section{Evaluation of the Performance of the Seed Paddy Cleaning Machine}

Evaluation of machine performance helps to know how well the machine performs the job to which it is designed for, and whether it is profitable or not (Roth 1975). According to Roth (1975), all possibilities of the machine should be evaluated objectively. Therefore, to evaluate the performance of the seed paddy cleaning machine, parameters such as separation percentage of large size impurities, light impurities and same size impurities, theoretical capacity of the machine, effective capacity of the machine, efficiency of the machine, mechanical breakdowns and ergonomic aspects and handling were considered.

When finding the separation percentages of impurities such as large size impurities, light impurities and stones, the initial amount of those impurities (before cleaning) should be known. Therefore, five samples of paddy (10 $\mathrm{kg}$ of each) were prepared manually removing all the impurities carefully and known amounts of each impurity as $250 \mathrm{~g}$ of large size stones, $250 \mathrm{~g}$ of same/small size stones, $250 \mathrm{~g}$ of straw particles, and $250 \mathrm{~g}$ of unfilled seeds were added to each sample purposely.

First, one batch of paddy (10 kg) was added to the sieve and operated the machine to complete sieving and time taken to complete one batch (10 kg of paddy), amounts of collected large impurities, light impurities and stones were counted separately. Five replicates were carried out. 
Then, the machine was continuously operated for one hour and output were measured. Impurities separation percentages based on the size were compared with Completely Randomized Design (CRD) with ANOVA and mean separation was carried out using Tukey mean separation method ( $p \leq 0.05)$.

Theoretical capacity of the machine $\left(\mathrm{kgh}^{-1}\right)$ $=(3600 \mathrm{~s} / \mathrm{h} \mathrm{x} 10) /$ time taken for one batch (s)

Effective capacity of the machine $\left(\mathrm{kgh}^{-1}\right)=$ Amount of paddy cleaned within one hour

Efficiency of the machine (\%) $=$ (Effective capacity/ Theoretical capacity) x 100

Large impurities separation $(\%)=($ Amount of collected large impurities (g)/ 250g) x 100

Light impurities separation $(\%)=($ Amount of collected light impurities (g)/ 250g) x 100

Same size impurities separation $(\%)=$ (Amount of collected large impurities (g)/ $250 \mathrm{~g}) \times 100$

\section{Results and Discussion}

After a series of trails and some modifications, a successful paddy cleaning machine was fabricated. Total cost of production, including both material and labor for the construction of the machine was LKR. 64,000. The detail cost evaluation is shown in Table 3.

Table 3: Detail cost evaluation

\begin{tabular}{lr}
\hline Item & Cost (LKR) \\
\hline Electric motor & 27,000 \\
Electric blower & 4,000 \\
Belt and pulleys & 3,000 \\
Sheet metal & 1,000 \\
'L' angled iron & 9,000 \\
Flat iron & 1,500 \\
Nut and bolts & 500 \\
Labour $(20$ h) & 18,000 \\
\hline Total & $\mathbf{6 4 , 0 0 0}$ \\
\hline
\end{tabular}

The fabricated paddy cleaning machine with its major components is shown in Plate 1.

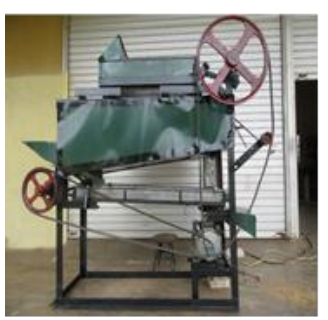

A

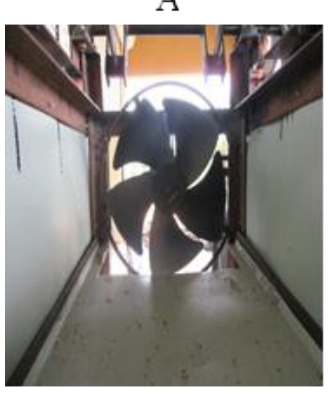

C

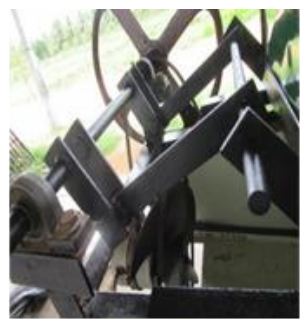

B

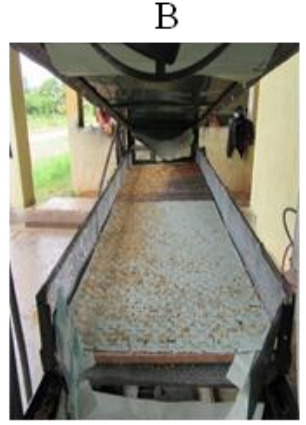

D
Plate 1: Fabricated machine with its major components.

A - Front view, B - Crank shaft of the sieve, $C$ - Blower of the aspirator, D - Vibrating plate of destoner 


\section{Specifications of Seed Paddy Cleaning Machine}

Specification of the fabricated seed paddy cleaning machine is shown in Table 4. As this new machine is for small and medium scale seed paddy producers, the overall dimensions are smaller than the commercially available large scale seed paddy cleaners. Most of the available large scale paddy cleaners in Sri Lanka have more than $1000 \mathrm{~kg} \mathrm{~h}^{-1}$ capacity. Some paddy cleaners in large scale rice mills have more than $10000 \mathrm{~kg} \mathrm{~h}^{-1}$ capacity.

Table 4: Specification of the fabricated seed paddy cleaning machine

\begin{tabular}{ll}
\hline Machine particular & Specification \\
\hline Overall length & $1650 \mathrm{~mm}$ \\
Overall width & $650 \mathrm{~mm}$ \\
Overall height & $1460 \mathrm{~mm}$ \\
Machine Capacity & $252 \mathrm{kgh}^{-1}$ \\
Power requirement & $3 \mathrm{~kW}$ with $1400 \mathrm{rpm}$ \\
& electric motor \\
Power transmission & A56 V belts and \\
& Pulleys \\
Sieve dimensions & $760 \mathrm{~mm} \mathrm{x} 510 \mathrm{mmx}$ \\
& $150 \mathrm{~mm}$ \\
Eccentric radius of sieve & $100 \mathrm{~mm}$ \\
shaft & $960 \mathrm{rpm}$ \\
Vibrating plate & $1180 \mathrm{~mm} \times 450 \mathrm{~mm}$ \\
dimensions & $20 \mathrm{~mm}$ \\
\hline
\end{tabular}

\section{Performance of Seed Paddy Cleaning Machine}

The performance of the seed paddy cleaning machine was determined by the means of theoretical capacity, actual capacity, efficiency, large impurities separation percentage, light impurities separation percentage and same size impurities separation percentage. All these parameters were calculated using the average values of five replicates. The table 5. shows the calculated values for these parameters.

Table 5: Performance of the seed paddy cleaning machine

\begin{tabular}{lc}
\hline Parameter & $\begin{array}{c}\text { Calculated } \\
\text { average }\end{array}$ \\
\hline Theoretical capacity $\left(\mathrm{kgh}^{-1}\right)$ & 319 \\
Actual capacity $\left(\mathrm{kgh}^{-1}\right)$ & 252 \\
Efficiency (\%) & 79 \\
Large impurities separation (\%) & 96 \\
Light impurities separation (\%) & 74 \\
Same size impurities separation (\%) & 86 \\
\hline
\end{tabular}

As per the figures given in the table 5, the actual capacity of the seed paddy cleaning machine was $252 \mathrm{kgh}^{-1}$ under $79 \%$ efficiency. The capacity of a cereal cleaner developed by Okunola (2015) is $1040 \mathrm{kgh}^{-1}$ under $71 \%$ of efficiency. Although, the capacity of the newly developed seed paddy cleaner is lower than the capacity of cereal cleaner, the higher efficiency of the machine reflects that, time wastage during the 
operation is very low compared to the cereal cleaner. The separation of large impurities was 96\% and it was observed that, some large size particles have passed through the mesh of the sieve, and they were separated at the same size impurities separation system (at vibrating plate). But the capacity of the same size separation system is only $86 \%$ and it reflects that, the system should be further improved. The light impurities separation percentage of the machine is $74 \%$ and the reason for this lower value is that many of light impurities added purposely had been separated at the large size impurities separation system. Separation percentages of large size impurities, light impurities and same size impurities were significantly different from each other $(p \leq 0.05)$ (Table 6).

Table 6: Separation percentages of different size impurities

\begin{tabular}{lc}
\hline Types of impurities & Mean Value \\
\hline Large size impurities & $74.25^{\mathrm{a}}$ \\
separation percentage & \\
Light impurities separation & $85.75^{\mathrm{b}}$ \\
percentage & \\
Same size impurities & $95.75^{\mathrm{c}}$ \\
separation percentage & \\
\hline
\end{tabular}

Values with different characters have significant difference at $p \leq 0.05$.

It is very important to mention that, totally all the light impurities added before the evaluation were separated from the machine. The separation efficiency of the rice cleaner cum grader developed in Nigeria was $63.97 \%$ - 94.29\% (Okunola et al. 2018). According to a study carried out by Ashwin et al. (2017) on the designing, fabrication and performance evaluation of a seed paddy cleaner, the dust and stone separation percentages were reported as $58 \%$ and $88 \%$ respectively. When compared to the performance of these machines (Okunola et al. 2018; Ashwin et al. 2017), the cleaning performance of the newly developed seed paddy cleaning machine is satisfactory, and it is in the range of $74.25 \%-95.75 \%$.

\section{Conclusions}

The newly developed seed paddy cleaning machine consist with four major systems as large size, light and same size or smaller impurities separation system and power transmission system. Further, it could be recommended for small and medium scale seed paddy producers with the capacity of $252 \mathrm{kgh}^{-1}$ with $79 \%$ efficiency. The paddy cleaned by the machine can achieve the standards of the seed paddy recommended by the Department of Agriculture, Sri Lanka. Due to the very low production cost of the machine (LKR. 64,000.00), it is much affordable for small or medium scale paddy farmers in Sri Lanka. The machine can be further developed with a magnetic separator for removing iron particles. 
Conflicts of Interest: The authors have no conflicts of interest regarding this publication.

\section{References}

Akinnuli, B 0, Osueke, C O, Agboola, P P I 0 O \& Adediran, A A 2015, Design Concepts Towards Electric Powered Gari Frying Machine. International Journal of Scientific and Engineering Research. 6(5). 10431050. Available at: https://www.resear chgate.net/publication/278028721 Design Concepts Towards Electric Powered Gari Frying Machine.

Ashwin, S, Manish N, Nishith S, Rhea D'mello, Vinoda N, Yathish K \& Poornesh M 2017, Design and Fabrication of Paddy Cleaning Machine, Journal of Mechanical Engineering and Automation 2017, 7(5): 145-149, DOI: 10.5923/j.jmea.20170705.04

DOA, 2014, Department of Agriculture, Rice Cultivation. Available at: https://doa.gov.lk /rrdi/index.php? option=com_sppage build er $\&$ view $=$ page $\& i d=42 \&$ lang=en. $[$ Accessed 29 Mar. 2020].

Engineers Edge, 2018, Geometric Boundaries IV. Available at: https://www. engineersedge.com/material_science/yield_ strength.htm. [Accessed 29 Mar. 2020].
Khurmi, R S \& Gupta, J K 2005, A Text Book of Machine Design. New Delhi: Eurasia Publishing House (PVT.) LTD.

Khurmi, R S \& Gupta, J K 2005, Theory of Machine, New Delhi, S.Chand and Company Limited.

Mohsenin, N N 1978, Physical properties of plant and animal materials: Structure, physical characteristics and mechanical properties. $1^{\text {st }}$ ed. New York: Gordon and Breach Science Publishers.

Nguyen, V N (2020), Rice production, consumption and nutrition -Available at: https://www.fao.org/3/Y4347E/y4347e02 .htm [Accessed 20 Nov. 2021].

Okunola, A A, Isaac-Bamgboye, A, Olyanju, A, Osueke, C O \& Alhassan, E A 2018, Development of a Rice Cleaner Cum Grader for Cottage Industry Processors in Nigeria. International Journal of Mechanical Engineering and Technology. 9(11); 23392351. Available at: https://www.iaeme. com/MasterAdmin/uploadfolder/IJMET 09 11 248/IJMET 0911 248.pdf.

Okunola, A, Igbeka, J \& Arisoyin, A 2015, Development and Evaluation of a Cereal Cleaner. Journal of Multidisciplinary Engineering Science and Technology (JMEST), 2 (6); 1587-1592. 
Reddy, B \& Chakraverty, A 2004, Physical Properties of raw and Parboiled paddy. Biosystem Engineering. 88(4); 461-466. Available at: http://agris.fao.org/agrissearch/search.do?recordID=US201300945 075 [Accessed 29 Mar. 2020].

Roth, L O, Crow, F R, \& Mahoney, G W A 1975, An Introduction to Agricultural Engineering 2nd ed. Maryland: Aspen publishers.

Senevirathna, J G D T, Mettananda, K A \& Bogahawatta, S 2008, A study on the Present status of seed paddy production in Sri Lanka. Annals of the Sri Lanka Department of Agriculture, pp 177-189. [online] Available at: https://issuu.com /afacipdf/docs/a_study_on_the_present_sta tus_of_se [Accessed 29 Mar. 2020].

Shahbandeh, M 2017, Rice statistics and facts. [online] Available at: https://www .statista.com/topics/1443/rice/. [Accessed 29 Mar. 2020].
Shetty, A, Nayak, M, Shetty, N, D’mello, R, Naik, V, Yathish, K, \& Poornesh, M 2017, Design and Fabrication of Paddy Cleaning Machine. Journal of Mechanical Engineering and Automation. 7(5);145-149. doi: 10.5923/j.jmea.20170705.04.

Tata, $R$ P 2012, Mechanical Power Transmission Fundamentals. [online] Available at:https:// www. cedengineering .com/upload/Mechanical\%20Power\%20Tr ansmission.pdf [Accessed 05 June 2014].

Weerasena, S L \& Madawanarachchi 2014, Improving quality seed supply in rice. Department of Agriculture. [online]. Available at: http://agrilear ning.goviya.lk /Paddy/Paddy_Research/Paddy_pdf/A11.p df. 